\title{
West Nile virus surveillance and diagnostics: A Canadian perspective
}

\author{
Michael A Drebot $\mathrm{PhD}^{1}$, Robbin Lindsay $\mathrm{PhD}^{1}$, lan $\mathrm{K}$ Barker $\mathrm{DVM}^{2}$, Peter A Buck DVM ${ }^{3}$, \\ Margaret Fearon $\mathrm{MD}^{4}$, Fiona Hunter $\mathrm{PhD}^{5}$, Paul Sockett $\mathrm{PhD}^{3}$, Harvey Artsob $\mathrm{PhD}^{1}$
}

MA Drebot, R Lindsay, IK Barker, et al. West Nile virus surveillance and diagnostics: A Canadian perspective. Can J Infect Dis 2003;14(2):105-114.

A surveillance program has been in place since 2000 to detect the presence of West Nile virus (WNV) in Canada. Serological assays are most appropriate when monitoring for human disease and undertaking case investigations. Genomic amplification procedures are more commonly used for testing animal and mosquito specimens collected as part of ongoing surveillance efforts. The incursion of WNV into this country was documented for the first time in 2001 when WNV was demonstrated in 12 Ontario health units during the late summer and fall. In 2002 WNV activity was documented by avian surveillance in Ontario by mid-May with subsequent expansion of the virus throughout Ontario and into Quebec, Manitoba, Saskatchewan and Nova Scotia. Human cases were recorded in both Ontario and Quebec in 2002 with approximately 800 to 1000 probable, confirmed and suspect cases detected. The possible recurrence and further spread of WNV to other parts of Canada in 2003 must be anticipated with potential risk to public health. The continued surveillance and monitoring for WNV-associated human illness is necessary and appropriate disease prevention measures need to be in place in 2003.

Key Words: Corvids; Diagnostics; Humans; Mosquitoes; Surveillance; West Nile virus

\section{La surveillance et le diagnostic du virus du Nil occidental : Une perspective canadienne}

\begin{abstract}
RÉSUMÉ : Un programme de surveillance est en place depuis 2000 pour déceler la présence du virus du Nil occidental (VNO) au Canada. Les titrages sérologiques conviennent le mieux pour surveiller la maladie humaine et entreprendre des investigations de cas. Les protocoles d'amplification du génome sont surtout utilisés pour évaluer les spécimens d'animaux et d'insectes recueillis dans le cadre des efforts de surveillance continus. L'incursion du VNO au pays a été documentée pour la première fois à la fin de l'été et à l'automne 2001, lorsque le VNO a été dépisté dans 12 unités de santé ontariennes. En 2002, l'activité du VNO a été documentée dès la mi-mai en Ontario grâce à la surveillance aviaire, et le virus s'est ensuite propagé en Ontario, au Québec, au Manitoba, en Saskatchewan et en Nouvelle-Écosse. Des cas humains ont été déclarés tant en Ontario qu'au Québec en 2002, de 800 à 1000 cas probables, confirmés ou présumés ayant été décelés. Il faut prévoir le potentiel de récurrence et de propagation du VNO dans d'autres parties du Canada en 2003, ainsi que le risque possible pour la santé publique. La surveillance et l'observation continues de la maladie humaine associée au VNO s'imposent, et des mesures de prévention pertinentes de la maladie doivent être en place pour 2003.
\end{abstract}

$\mathrm{T}$ he unexpected incursion of West Nile virus (WNV) into North America occurred during the summer of 1999 when an outbreak of neurological illness among humans, birds and horses was identified in the metropolitan area of New York City $(1,2)$. This outbreak (62 human cases, including a visiting Canadian) was the first time that laboratory-confirmed cases of WNV disease had been observed in the Western hemisphere. By the end of 2002, the geographic range of WNV had expanded to 44 states, the District of Columbia and five Canadian provinces (3). In 2002, approximately 3000 cases of meningoencephalitis (ME) and over 1000 cases of WNV fever had been documented in the United States and Canada, making this epidemic the largest arboviral ME outbreak ever recorded in the 'New World' and the largest WNV ME outbreak ever seen worldwide. This review describes the ecology and epidemiology of WNV and focuses on the diagnostic tests used to detect infection in birds, mosquitoes and people, and on the surveillance programs used to detect virus activity in Canada.

\section{VIRUS TAXONOMY, ECOLOGY AND EPIDEMIOLOGY}

WNV is a member of the flavivirus genus (Family Flaviviridae) (4). All flaviviruses are approximately $40 \mathrm{~nm}$ in diameter and are composed of an icosahedral nucleocapsid surrounded by a lipid bilayer-containing envelope and membrane proteins $(4,5)$. The genome is a single strand of ribonucleic acid (RNA) of positive polarity that contains 11,000 nucleotides and encodes several structural and nonstructural proteins. There are over 70 distinct agents within the Flaviviridae and WNV belongs to the Japanese encephalitis (JE) antigenic serogroup, which includes St Louis encephalitis (SLE) virus, JE virus and Murray Valley encephalitis virus, all of which can cause encephalitis in humans $(4,6)$.

${ }^{1}$ Zoonotic Diseases and Special Pathogens, National Microbiology Laboratory, Health Canada, Winnipeg, Manitoba; ${ }^{2}$ Canadian Cooperative Wildlife Health Centre, Ontario/Nunavut Region, Department of Pathobiology, Ontario Veterinary College, University of Guelph, Guelph; ${ }^{3}$ Foodborne, Waterborne, and Zoonotic Infections Division, Centre for Infectious Disease Prevention and Control, Health Canada, Ottawa;

${ }^{4}$ Virology/Immunodiagnostics, Perinatal and Vaccine Preventable Diseases Section, Ontario Ministry of Health and Long Term Care,

Laboratories Branch, Toronto; ${ }^{5}$ Department of Biological Sciences, Brock University, St Catharines, Ontario

Correspondence and reprints: Michael A Drebot, Room 4810, 1015 Arlington Street, Winnipeg, Manitoba R3E 3R2.

Telephone 204-789-6059, fax 204-789-2082, e-mail Mike_Drebot@hc-sc.gc.ca 
The majority of flaviviruses are transmitted by either mosquitoes or ticks and require a vertebrate reservoir host for amplification. For WNV and other members of the JE serogroup, transmission occurs when mosquitoes feed on competent reservoir hosts, and these hosts develop a high titre viremia and infect subsequent cohorts of feeding mosquitoes (7). This enzootic amplification cycle typically involves birdfeeding mosquitoes (usually Culex species) and a variety of avian hosts. Depending on the size of the vector mosquito and avian reservoir populations and abiotic factors, such as temperature and timing of enzootic amplification, 'spillover' of WNV from the bird-mosquito cycle to other hosts, such as horses or people, can occur. Mosquito species that are general feeders, and take blood meals from birds and mammals, likely act as the principal 'bridge vectors' of WNV (7-9). Because people and horses do not develop a sufficient viremia to infect mosquitoes they do not play a role in virus amplification and are considered to be incidental or dead end hosts $(5,10)$.

West Nile virus was first isolated in 1937 from the blood of a febrile patient in the West Nile province of Uganda (11). Before 1994 sporadic cases of WNV infection were reported, with only a small number of outbreaks occurring in parts of Africa, the Middle East, Europe and Asia (12). In these outbreaks, severe neurological disease was rare and most patients were either asymptomatic or developed only mild febrile illness. In contrast, from 1994 to 2002 outbreaks with significant numbers of encephalitis cases have occurred in Algeria, Morocco, Romania, Tunisia, Congo, Italy, Israel, Russia, France, the United States and Canada (13).

Worldwide, WNV has a very broad geographic range; however, the exact mechanism governing the distribution of this virus has not been resolved. Virus activity in northern Africa (eg, Tunisia, Morocco) precedes or coincides with WNV epidemics in Europe, which supports the possible role of migratory birds in virus dispersal (14). Presumably local mosquitoes acquire WNV infection by feeding on infected migratory birds and foci of enzootic amplification occur thereafter. In North America, it is likely that migratory birds play a similar role in long range transport of WNV; however, it is also possible that nonmigratory flights of infected birds can contribute to short range (less than $50 \mathrm{~km}$ ) movement of the virus (15).

In contrast to other members of the JE serogroup currently circulating in North America, WNV has caused a high level of mortality in a large number of North American bird species (16). Members of the Corvidae (eg, crows, blue jays, ravens) appear to be particularly susceptible to mortality following exposure to WNV (16). In part due to this susceptibility, corvids in general and crows in particular, have been the primary target species for dead bird surveillance programs in North America. In fact, large numbers of dead crows (and other bird species) were reported at the same time as human cases during the 1999 outbreak in New York City and the first isolates of WNV in North America were from birds $(17,18)$.

The apparent change in the frequency of serious health effects associated with illness due to WNV, as indicated by recent ME outbreaks, may be due to the introduction and circulation of more virulent strains of the virus. Phylogenetic analysis has grouped WNV isolates into two major lineages that diverge by up to $30 \%$ in nucleotide sequence $(19,20)$. Isolates from Europe and North America cluster as a genogroup in lineage 1 , whereas African strains are present in lineages 1 and 2. Viruses from lineage 2 are rarely associated with human illness and have been isolated only in sub-Saharan Africa and Madagascar. Genetic characterization of isolates involved in recent outbreaks indicates significant sequence homologies among these strains and potentially these genotypes may share virulence markers (20). However, geographic and demographic parameters, such as age structure and regional seroprevalence or background immunity, can also play roles in the occurrence of epidemics. The background immunity to WNV in endemic areas of Africa can be greater than 50\% (21). However, based on serological surveys conducted in Romania and New York City following WNV outbreaks, seroprevalence was only $2 \%$ to $4 \%(22,23)$. This suggests that most of the population in these areas was not immune to WNV and the incursion of WNV resulted in large numbers of cases of human illness.

Advanced age is one of the most important risk factors for severe neurological disease after infection with WNV. Although serosurveys conducted in Bucharest and New York city indicate that one in 150 to 300 individuals exposed to the virus develops $\mathrm{ME}$, the incidence of neurological illness is 10 times higher in persons 50 to 60 years of age and over 40 times higher in those 80 years of age or older $(22,23)$. During the 2002 WNV outbreak in North America, individuals older than 50 years of age were most at risk for acquiring WNV ME and febrile disease (3; R Jin, personal communication). In the United States the median age of people with WNV ME was 59 years and $9 \%$ of these individuals died (3).

Significant numbers of WNV-infected patients who develop severe neurological illness demonstrate slow recovery and significant long term sequelae, which include physical symptoms such as muscle weakness, fatigue, headache and effects on cognitive function, including confusion, depression and memory loss (24). In approximately half of these cases, patients have self-reported that they had still not fully recovered 12 months after illness onset.

In 2002, nonmosquito-related modes of transmission were documented for the first time (3). In the United States these included person to person transmission by organ donation, blood transfusion and possibly breast feeding. Intrauterine infection was reported and several cases of laboratory-acquired infections were also detected. One probable case of WNV transmission by blood transfusion was also reported in Canada, which led to the removal of thousands of units of blood products that may have been contaminated with the virus (25).

\section{MONITORING FOR WNV-ASSOCIATED HUMAN DISEASE}

\section{Features of WNV infection}

To better appreciate the utility of various diagnostic approaches for detecting WNV a basic understanding of the clinical course of viral infection is needed. The incubation period of WNV is not precisely known, though it is believed to range from three to 14 days. Viremia is normally low in most individuals (an average of less than 100 plaque forming units $/ \mathrm{mL}$ of blood) and usually decreases significantly one to two days after symptom onset $(21,26)$. Immunoglobulin (Ig) M antibody is generally not detected until after the viremic phase. Occasionally certain patients (particularly immunocompromised individuals) may display prolonged viremia and delayed immune responses (27).

The mechanism of viral spread and the role of the immune system in limiting dissemination of viral infection is poorly 
understood. In studies using nonhuman primates and rodents, WNV replication occurred in several sites, including lymph nodes, spleen, kidney, muscle and the central nervous system $(28,29)$. Further research is required to better define the cellular targets for WNV infection; however, in vitro experiments indicate that cells of myeloid origin (tissue macrophages and dendritic cells) are targeted by WNV (30). In the early 1950s a number of cancer patients were infected with the Egypt 101 strain of WNV in hopes of inhibiting their neoplasms (31) Most patients presented with mild febrile illness, but one individual was diagnosed with encephalitis and later died. Virus was isolated from the patient's lymph node, spleen, lung and liver (31).

The possible persistence of virus in tissues is of concern with respect to organ donations. A Russian study in the 1980s showed that organs from infected monkeys harboured viable virus several months after inoculation (28). Further studies on WNV persistence in various vertebrate hosts are warranted to better understand by what means WNV could persist or become reactivated in organs. The long term persistence of IgM antibody in certain individuals (see below) may be evidence that latent infections can occur in humans (32).

Approximately $80 \%$ of WNV infections are asymptomatic; however, when it occurs, WNV disease can range from mild febrile illness (more than than 95\% of symptomatic infections) to meningitis and/or encephalitis (less than $1 \%$ of exposures) $(5,33)$. People infected with WNV frequently experience fever, headache and other nonspecific symptoms that typically last for several days. Symptomatic individuals can also display a variety of other signs and symptoms, including nausea, vomiting, macular papular rash, chills, abdominal pain, muscle weakness, photophobia, conjunctivitis, confusion and slurred speech $(1,33)$. For certain patients a febrile prodrome is immediately followed by encephalitis. The occurrence of more severe neurological manifestations, such as poliomyelitis-like syndrome were documented for the first time during the 2002 outbreak $(34,35)$.

Typically, people with meningitis or encephalitis of viral origin display cerebrospinal fluid (CSF) profiles with pleocytosis. CSF samples from WNV-infected individuals exhibit leukocyte counts ranging from 0 to 1782 cells $/ \mathrm{mm}^{3}$, usually with a predominance of lymphocytes (33). Protein levels are universally elevated (51 to $899 \mathrm{mg} / \mathrm{dL}$ ) and glucose levels are normal.

\section{Diagnostics}

A number of diagnostic procedures are currently available for documenting cases of WNV disease (Figure 1) and these can be divided into virus isolation, serological assays, detection of WNV antigen and nucleic acid amplification tests (NATs). Serological procedures are the methodologies of choice for diagnosing cases of WNV disease. However, for the screening of human blood supplies and the testing of immunocompromised individuals with extended viremia, the use of NATs is currently of greatest value.

Virus isolation: Isolation of WNV from blood, other tissues or CSF, is rare due to the low concentration of virus found in these samples and the transient nature of viremia. However, WNV was recently isolated for the first time from the blood of a patient with encephalitis (27). This person was taking immunosuppressive drugs, which probably contributed to a persistent and relatively intense viremia that increased the

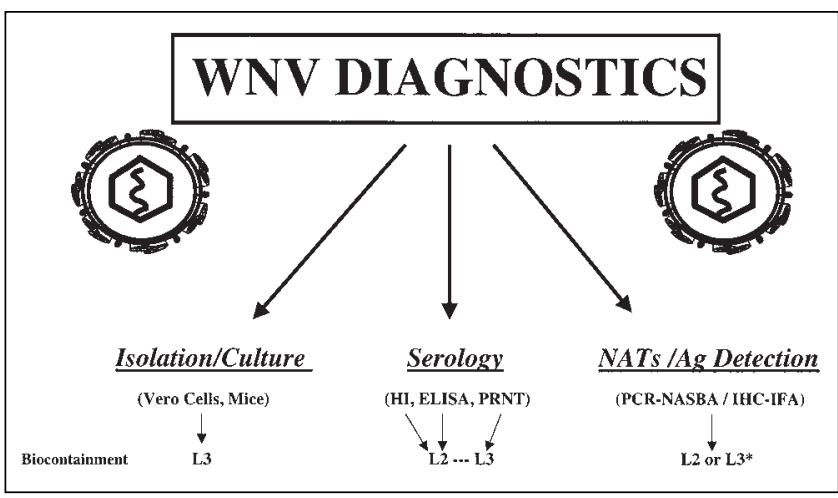

Figure 1) West Nile virus diagnostic platforms (including biocontainment levels at which procedures are performed). *The manipulation of bird tissue may require level 3 (L3) containment. This is advised due to high viral load in infected corvids and other bird species. Ag Antigen; HI Hemagglutination inhibition; IHC-IFA Immumohistochemistryimmunofluorescence assay; L2 Level 2; NASBA Nucleic acid sequence based amplification; NATs nucleic acid amplification tests; PCR Polymerase chain reaction; PRNT plaque-reduction neutralization test

likelihood of viral isolation. Staff at the United States Centers for Disease Control and Prevention (CDC) have also isolated virus from serum, CSF, liver and brain samples of patients infected in 2002 (R Lanciotti, personal communication). The increased success in isolating live virus from patients probably reflects the large number of cases observed in 2002, as opposed to the refinement of techniques of virus culture. The low sensitivity and labour intensive nature of this methodology, as well as the requirement of level three biocontainment for viral propagation, will continue to make viral isolation a rarely used procedure.

Serological assays: The detection of WNV-specific antibodies between the acute (one to seven days postonset of symptoms) and convalescent phases of illness (two to three weeks after symptoms) provides definitive serological evidence of infection. Hemagglutination inhibition (HI) assays and IgG ELISA can be used to demonstrate fourfold or greater rises in antibody levels in acute and convalescent serum samples (36-38). However, antibodies to flaviviruses, such as the members of JE serogroup or dengue serotypes and yellow fever virus, crossreact extensively in the HI test and IgG ELISA. Therefore, tests like the plaque-reduction neutralization test (PRNT) must be used to differentiate between these viruses (36).

The HI test can detect both IgM and IgG antibodies but cannot differentiate between these two kinds of immunoglobulins (37). Flavivirus antibodies are quite cross-reactive to antigens prepared from dengue and JE serocomplex virus cultures; however, a higher level of specificity is observed when WNV-specific antisera (particularly in the case of acute serum) is tested against WNV antigen versus other flavivirus antigenic preparations. Although the procedure is more labour intensive than the ELISA, the HI assay has the advantage that it does not require antispecies conjugates so it can theoretically be applied to serum samples from any species (36).

The IgM ELISA is becoming more common as the diagnostic test of choice for detecting the presence of antibodies against WNV and other flaviviruses (39). The sensitivity of the assay is high when applied to appropriately timed serum and CSF specimens, and potentially would provide positive or probable results using only acute serum from patients with 
WNV-compatible illness. The IgM ELISA also cross-reacts with other flaviviruses and, in fact, the outbreak in New York City in 1999 was initially misdiagnosed as SLE by ELISA serology $(39,40)$. However, the assay can be more specific than other serological procedures and shows promise as a 'frontline' screening test in discriminating between WNV infections and exposures to dengue or SLE viruses. By comparing the optical density (OD) of a patient's serum to a normal human antibody control using West Nile virus and assorted flavivirus antigens (obtained by dividing the OD of the colorimetric reaction produced by patient serum by the OD of a normal human antibody control) infections with WNV virus can be correctly identified more than $90 \%$ of the time (39).

There are a number of factors to consider when choosing to implement the IgM ELISA or interpreting results from such a diagnostic procedure. First, unlike the $\mathrm{HI}$ test there are several components (eg, viral specific monoclonal antibodies) necessary for performing the assay that are not as yet widely or commercially available. Second, although the cross-reactivity of IgM ELISA is significantly lower than that observed with HI or IgG ELISA, the laboratory-based documentation of initial cases of WNV infection within a given jurisdiction or health unit should still include confirmatory assays such as PRNT or NATs (see below). Third, most individuals who are exposed to WNV are asymptomatic or develop only mild symptoms and WNV IgM antibody can persist for a year or more following infection (32). Therefore in regions where WNV activity has been detected in the previous year, it is possible that people in these regions may still have IgM antibody from a previous infection that is unrelated to their current clinical illness. In this situation, it may be necessary to collect convalescent sera and show diagnostic changes in antibody titres by $\mathrm{HI}, \operatorname{IgG}$ ELISA or PRNT to verify some of these acute infections. Fourth, patients who have had one or more previous exposures to other flaviviruses will probably give a much less specific result on the IgM ELISA (41; R Lanciotti, personal communication). For example, patient serum to normal human antibody ratios for different antigens may be quite similar among flavivirus, making it difficult to incriminate a particular flavivirus as the source of an infection. Similarly, for individuals who have been exposed to different flaviviruses over short time intervals, the IgM test may give a false negative due to down regulation of IgM antibodies and a preferential IgG immune response. Finally, during the 1999 and 2000 outbreaks in New York, CSF samples from 95\% of ME cases were IgM-positive; however, $10 \%$ of serum samples obtained within eight days of symptom onset were negative $(33,42)$. Other studies have also shown that IgM antibodies may not always be present soon after illness (seven to eight days) (43), so it is important to interpret laboratory results with care and obtain additional serum samples from patients meeting suspect case definition criteria. This is particularly true for individuals who are immunocompromised.

The detection of antibody in CSF is a sensitive procedure and usually indicates a current infection. However, the collection of CSF requires invasive lumbar punctures and it may not always be practical to obtain these samples. In addition, the concentration of antibody in CSF may not be of high titre and for this reason CSF samples are usually not diluted when processed for serological testing. This can impact on the use of CSF for various other diagnostic procedures because limited amounts of CSF are usually available.
The neutralization test is still the 'gold standard' for detecting arbovirus specific antisera. Various types of neutralization assays are available; however, the PRNT is usually the procedure of choice (36). Neutralization antibodies usually appear later during the course of infection and significant titres are most often observed two to three weeks after onset of symptoms. The PRNT can take a week or more to perform and the use of propagated WNV in the assay requires enhanced biocontainment facilities. Recent technological advances, such as flavivirus ELISA-microneutralization tests will allow for less labour intensive and higher throughput procedures for neutralization-based assays (44). The possible availability of attenuated vaccine candidate strains may allow the neutralization procedures to be performed within level two biocontainment, thus making this test more widely available (R Lanciotti, personal communication). As well, methodologies such as WNV competitive or blocking ELISA show promise for supplementing and/or serving as alternatives to the PRNT (R Hall, personal communication).

Alternative serological procedures such as immunofluorecence assays or 'antibody capture dipstick or wicking' kits are commercially available for many flaviviruses $(36,40)$. These types of methodologies have been used for a variety of arboviruses and have the advantage of being relatively straightforward procedures to perform. However, the sensitivity and specificity of these tests for WNV serology require further evaluation.

Detection of WNV antigen: The titre of virus in blood, sera or CSF samples is normally too low for efficient detection by antigen capture ELISA and other antigen capture formats that are designed primarily to detect virus particles or protein in bird tissues or in mosquitoes $(45,46)$. However, immunohistochemistry methodologies have been successfully used to demonstrate viral antigen in brain tissue from people or horses who died from WNV infection. As well, immunofluorecence assays have been utilized for the detection of virus in cell culture and various types of tissue samples.

Nucleic acid amplification tests: Nucleic acid amplification procedures are now routinely used to detect the presence of infectious agents in a variety of specimens (47). Standard reverse transcription (RT)-polymerase chain reaction (PCR), real time RT-PCR and nucleic acid sequence-based amplification procedures are available for most flaviviruses including WNV $(48,49)$. Although NATs have the potential to simplify and improve the diagnosis of flavivirus CNS infections, these procedures must be carefully performed and results interpreted with caution. Previous studies have shown that approximately $50 \%$ of CSF samples from confirmed cases of WNV ME are positive for WNV RNA, whereas blood and serum contain detectable WNV genome only $10 \%$ of the time (48). The decreased sensitivity of NATs is not due to the test itself (ie, nucleic acid sequence-based amplification and real time TaqMan (Taqman Laboratory, Pittsburgh) assays are able to detect as few as 0.1 to 0.05 plaque forming units $/ \mathrm{mL}$ or 10 to 50 copies of genome) but the low titre and transient nature of viremia (or viral presence in CSF) decreases the likelihood that NATs will successfully detect virus in clinical samples. Shortly after the onset of symptoms, most patients have little or no virus in serum or blood samples; however, certain immunocompromised individuals may exhibit prolonged and more intense viremia. Establishing the laboratory capacity to use NATs for WNV diagnostics is useful because the detection 
of viral genome is a confirmatory assay (see below). However, it should be stressed that a negative NAT test is not adequate for diagnosis and must be complemented with serological assays. In addition, some PCR-based procedures are prone to cross-contamination and false positives can occur unless proper laboratory setup is established and appropriate negative controls are monitored.

Test variability, laboratory to laboratory variation: proficiency panels

All diagnostic tests should be standardized and validated with respect to sample preparation, assay procedures, positive-negative controls and test interpretation. For serological and PCRbased methodologies a panel of positive, equivocal and negative controls (ie, serum and/or RNA extracts) should be included to establish the sensitivity and specificity of the assays. Proficiency panels will be available to assure quality of WNV diagnostic procedures undertaken in Canadian laboratories in 2003.

\section{Specimen collection and diagnostic algorithms}

For patients suspected to have WNV neurological disease the most appropriate specimen is an acute serum sample collected within seven days of illness onset (CSF, if available, may also be tested for the presence of IgM antibodies). These samples can be tested using the HI test and/or ELISA. Not all patients infected with WNV develop antibodies during the acute phase, so follow-up samples may be needed in people with WNV-compatible disease. Significant patient serum to normal human antibody ratios (ie, 3 or greater) for IgM ELISA and high HI titres (ie, 320 or greater on WNV antigen) should be considered as valid parameters for designating cases as 'probable' (43). This is particularly true when patients reside or visit an area where other human cases of WNV infection have been confirmed. In addition, high static titres in paired sera may indicate that 'diagnostic rises' in antibody titre were missed because of inappropriately timed collection of samples; therefore, high titres in both acute and convalescent samples may also be appropriate as a diagnostic parameter for designating a case as probable (see below and Appendix I).

Due to the caveats associated with IgM testing it is encouraged that convalescent serum samples are taken 14 to 21 days after symptom onset. HI or IgG ELISA or PRNT can then be used to detect elevated titres (fourfold or greater) of antibody between acute and convalescent serum samples. Cases of WNV fever would be recorded following the same serological testing procedures. NATs can also be performed on CSF to detect viral genome. Although the sensitivity of NATs is low the detection of WNV RNA provides a rapid confirmatory result and may be useful for immunocompromised patients who are slow to produce antibody. The low sensitivity of viral isolation procedures and the necessity to use level three biocontainment for propagating WNV limits its use in most laboratories in Canada.

\section{THE ESTABLISHMENT OF A CANADIAN WNV SURVEILLANCE PROGRAM}

Following the incursion of WNV into the United States in 1999, Health Canada established the WNV National Steering Committee whose primary mandate has been to develop national guidelines for surveillance and response so that a coordinated system to monitor for WNV and response to pos- sible introduction of this virus into Canada was developed. The National Steering Committee has drawn its members from a variety of organizations and disciplines including representatives from various branches or centres in Health Canada (including the Population and Public Health Branch and the Pest Management Regulatory Agency), other federal agencies such as the Canadian Food Inspection Agency (CFIA), Environment Canada and the Department of National Defence, provincial ministries of health, the council of Chief Medical Officers of Health, various nongovernmental organizations such as the Canadian Cooperative Wildlife Health Centre (CCWHC) and members of various university faculties. Following the United States' template, the guidelines focused on key areas, including surveillance, education and prevention, and vector control and communications.

\section{WNV surveillance in Canada}

Systems for monitoring for virus activity: The WNV surveillance program in Canada has evolved to incorporate new information and diagnostic assays as they have become available. The focus for surveillance has been on birds, mosquitoes, horses (or other domestic animals) and humans.

Surveillance in bird populations has used enhanced passive surveillance for dead birds and active surveillance using sentinel chickens. In the former, as a result of the observation that corvids appear to be more susceptible to fatal WNV infection than other species of birds, surveillance has focused on dead corvids as an early indicator of virus activity in a local ecosystem. For greatest utility, the submission, testing and reporting of dead corvids needed to be timely so that patterns and intensity of mortality were recognized, and WNV detected sufficiently early to initiate public health measures to decrease the risk of infection in humans. In all provinces involved in dead bird surveillance, a system was established that encouraged the reporting of dead birds and carcasses of suitable quality were collected and shipped to either one of four CCWHC veterinary laboratories or certain provincial veterinary laboratories. Birds were either examined for pathological evidence of WNV infection (in 2000) and/or various tissue samples were extracted and tested in-house or shipped to Winnipeg for testing either in the National Microbiology Laboratory (NML) or CFIA laboratory. In Winnipeg, the testing of tissues was carried out by high throughput homogenization and RNA extraction procedures (NML) or immunohistochemistry (IHC) (CFIA in 2000 only). Isolated RNA was screened for the presence of WNV genome by real time TaqMan RT-PCR diagnostics. The RNA was re-extracted from positive samples and further tested by an additional panel of real time and one step RT-PCR assays. To confirm infection with WNV in birds from health units or municipalities that had not previously documented virus activity in the current year or to-date, viral isolation or immunological staining of tissue was also conducted. Lastly, the CCWHC organized a system for recording dead bird sightings and maintained a database for tracking bird submissions and reporting results of diagnostic testings to provincial public health authorities. This database was also used to generate detailed electronic maps of the geographic distribution of dead bird sightings and tested specimens (ie, positive and negatives). Since 2000 the focus of the dead bird surveillance program has narrowed from a relatively broad list of target species, to one targeting corvids only and crows only in some jurisdictions. Similarly, the diagnostic algorithm has evolved from 
gross pathological and histopathological examination followed by IHC or PCR, to molecular-based diagnostics only on all submitted samples.

Active surveillance using sentinel chickens was employed because this method has been used successfully in other arbovirus surveillance programs (eg, SLE and Western equine encephalitis [WEE]) throughout North America (49). Flocks of up to 10 chickens (of various breeds) were placed at a number of localities (from one to 18) in New Brunswick, Quebec, Ontario, Manitoba and Saskatchewan starting in June 2000. Blood samples were collected weekly or every two weeks and serum samples were tested by $\mathrm{HI}$ for evidence of antibodies to WNV. The apparent failure of the sentinel chicken surveillance system to provide an early warning of WNV activity in most jurisdictions using this methodology in the United States, prompted its discontinuation in much of Canada after 2000. Some jurisdictions continue to use sentinel chickens for surveillance for other arboviruses (eg, WEE) and serum are also screened for antibodies to WNV.

Because mosquitoes are the primary vectors of WNV, mosquito surveillance was undertaken in various jurisdictions in Canada to determine the species composition, relative abundance and seasonal patterns of activity of adult mosquitoes in different at-risk localities, and to test collected mosquitoes for evidence of WNV infection. The ultimate goals of mosquito surveillance were to gain a better understanding of the specific role that different mosquito species play in enzootic and epidemic transmission of WNV and to use this information to guide decision making concerning the need to implement control activities to suppress mosquito populations.

The scope and intensity of mosquito surveillance has followed a 'graded response' based primarily on real or perceived risk of WNV activity. During 2000 and 2001, surveys of adult or larval mosquito populations were conducted in parts of Atlantic Canada, Quebec and Ontario to define (or redefine) which mosquito species were present and regionally abundant in or around select urban centres in these provinces. Once WNV activity was documented in Quebec, Manitoba, Saskatchewan and Nova Scotia and recursion occurred in Ontario during 2002, the intensity of surveillance increased in most affected areas and greater emphasis was placed on timely testing of mosquitoes in order to estimate the level of risk for human exposure. Mosquitoes were collected using either CDC light traps baited with carbon dioxide, gravid traps or both. Trapping was typically conducted at least once per week in most jurisdictions. The start dates for sampling varied among jurisdictions; however, overall, most mosquito trapping was conducted during July, August and September. Traps containing mosquitoes were shipped via courier or delivered to university or pest control laboratories for sorting, identification and enumeration. During the identification process, cold chain conditions were maintained and identified mosquitoes were placed in vials, in pools of up to a maximum of 50 individuals, by collection date, location and species. Vials containing mosquitoes were frozen at $-80^{\circ} \mathrm{C}$ and most were shipped to the NML for diagnostic testing. In 2002 staff at Brock University in Ontario established a pilot project and also tested mosquitoes from six health units in southern Ontario. The protocol for testing mosquito pools was similar to that described for corvid tissues; however, confirmation was not routinely done by virus isolation. Data generated on the species composition, relative abundance and seasonal trends in mosquito activity typically flowed from the mosquito identification laboratories directly to the affected health units whereas the results of mosquito testing were reported to provincial health ministries that relayed this information to affected health units.

Surveillance for WNV in horses or in commercial bird facilities was conducted to estimate the impact of infection on these populations and to serve as an indicator of virus activity in rural communities, where it was anticipated that because of low human population density dead bird surveillance might not be as effective compared with urban centres. Veterinarians were informed of the clinical signs of WNV and were instructed to submit serum samples or brain tissue from suspect cases. Staff at the CFIA laboratory in Winnipeg performed PRNT on serum samples and RT-PCR on brain samples; however, during August 2002, the responsibility for diagnostic testing was transferred to provincial or private veterinary laboratories.

Enhanced passive surveillance for WNV in the human populations was conducted throughout the mosquito season in most jurisdictions in eastern and central Canada. Physicians were informed of the symptoms of WNV and encouraged to report suspect cases to local and provincial public health authorities. Probable WNV cases were individuals with appropriate clinical manifestations and flavivirus seroconversion using HI. Provincial public health laboratories in Quebec and Ontario performed the frontline HI testing and confirmation of WNV infection was by PRNT performed at the NML. Once WNV was detected in a province, varying degrees of active surveillance for human infections were undertaken depending on regional capacity (Canadian Provincial Laboratories, personal communications).

Results of surveillance activities from 2000 to 2002: Though WNV was reported in all counties of New York that border Ontario and Quebec during 2000, no evidence of virus incursion was documented in Canada. In 2001, the first WNV-infected bird ever conclusively identified in Canada was collected in early August in Windsor, Ontario (50). Subsequently, an additional $127 \mathrm{WNV}$-infected crows or Blue Jays were collected from 12 different health units in southern Ontario. A total of 38,625 mosquitoes of 27 different species were collected in 14 health units, grouped into 2989 pools and WNV was detected in 11 pools of Culex pipiens (5), Culex species (5) and $C$ salinarius (1) mosquitoes from two health units. In addition, overwintering female $\mathrm{C}$ pipiens were collected from these two health units in January 2002 and WNV viral RNA was detected in one of 59 pools ( $n=2593$ mosquitoes) tested. Although dead bird surveillance was conducted in Saskatchewan, Manitoba, Quebec and the Atlantic Provinces, evidence of WNV activity, outside of Ontario, was not observed. Human or horse cases were not detected during $2001(50,51)$.

In 2002, dead bird surveillance detected recursion of WNV in southern Ontario; however, the first infected bird was collected in mid-May, almost three months earlier than in 2001. Throughout the summer of 2002, WNV-infected dead birds were collected in 36 of 37 health units in Ontario and virus activity was documented for the first time in Quebec, Manitoba, Saskatchewan and Nova Scotia. Overall, a total of $563 \mathrm{WNV}$-infected corvids and greater than 16,500 sightings of dead corvids were reported in 2002. WNV infection was also documented in several other bird (eg, hawks, owls, domestic geese and gulls) and mammal species (ie, grey squirrels in 
southern Ontario and a Barbary ape from the Toronto Zoo (G Crawshaw, personal communication).

More than 191,500 mosquitoes from 42 different species collected in Ontario, Quebec and Manitoba were grouped into 17,031 pools and tested for infection with WNV. In 2002 WNV viral RNA was detected in 10 different species of mosquitoes. In total, eight, five and three species of mosquitoes with evidence of WNV infection were collected in Ontario, Quebec and Manitoba, respectively. More than $80 \%$ of WNVinfected mosquito pools were Culex species such as C pipiens, $\mathrm{C}$ restuans, or mixed genus pools (ie, mixtures of $\mathrm{C}$ pipiens and $\mathrm{C}$ restuans). These Culex species are known to feed preferentially on birds and are suspected to be the primary enzootic vectors of WNV in North America. Of the remaining eight infected species, some feed primarily on mammals (ie, Aedes vexans, Anopheles punctipennis, Ochlerotatus canadensis and O trivittatus) while the others (ie, C tarsalis, C salinarius, Coquillettidia perturbans and $\mathrm{O}$ triseriatus) have a wider host range that can include birds, humans and other mammals. Because of their feeding preference the latter species are suspected to be involved in transmission of WNV to humans or other mammals. However, at the present time, the precise role that any of these species has in virus transmission to humans has not been clearly defined. Regardless of species, most infected mosquitoes were collected from late July to early September and within most jurisdictions, consistent collection of infected mosquitoes occurred just before and throughout the period when human infections were occurring.

During 2002, approximately 360 cases of WNV infection in horses were reported in Saskatchewan, Manitoba, Ontario and Quebec. However, these numbers likely underestimate the overall burden of illness in equines because access to rapid and sensitive diagnostic tests was limited in most affected regions in Canada, especially early in the epizootic (51).

Human cases in Ontario were first reported in late August; however, the onset of symptoms for some patients was as early as August 3. As of February 2003, almost 400 probable or confirmed cases of WNV-associated disease had been documented in Ontario (50). In addition, several hundred suspect cases have also been detected and await further verification of etiology. The age range of patients (nine to 86 years of age) was generally similar to that observed in the United States and at least 10 individuals with WNV infection have died. In Quebec, only eight cases of WNV have been confirmed, including one death (52). Although WNV activity was not documented in Alberta, two confirmed human cases of WNV infection occurred in Alberta residents; however, both had histories of travel to areas where WNV was circulating and causing human infections (51).

The factors that govern WNV activity and infection in North America are unknown; however, in Ontario, human cases of WNV infection were reported predominately in health units that documented activity in 2001. This same area of southern Ontario (ie, Toronto to Sarnia) was the epicentre of human cases of SLE during a major outbreak in 1975 (49). This geographic region of Ontario typically experiences warmer temperatures throughout the year than other parts of Ontario. These conditions may have favoured virus amplification and 'spillover' into the human population by increasing the rate of mosquito development, which may have allowed additional mosquito cohorts to develop and also by decreasing the extrinsic incubation period (ie, time required for virus to replicate, such that mosquitoes are infectious) so that more mosquitoes would have had an opportunity to transmit WNV. Similarly, WNV activity was documented much earlier in most health units in southern Ontario than in other jurisdictions during 2002 and this early season amplification may have also contributed to the overall probability of enzootic amplification and subsequent human infections. In fact, early season WNV virus activity has been reported as a significant risk factor for human cases of WNV in the various jurisdiction in the United States (16). The mechanism that resulted in early season virus activity in southern Ontario has not been well defined. However, it is possible that WNV was transmitted horizontally via overwintered $\mathrm{C}$ pipiens populations, as reported in this paper, and when these mosquitoes emerged in the spring, localized foci of enzootic amplification were established. It is also possible that early migrant bird species reintroduced WNV into southern Ontario from wintering grounds in the United States during spring migration. If the former mechanism is operating, WNV may now be endemic in parts of southern Ontario and may not require annual reintroduction from areas further south to initiate virus amplification.

The mosquito data were used in most jurisdictions as an action point to enhance communications with the public regarding strategies to reduce risk of exposure to WNV such as wearing insect repellents. Few jurisdictions implemented larviciding or adulticiding programs to further reduce the risk of human exposure and the efficacy of any of these intervention strategies, including enhanced communications, was not formally evaluated.

\section{ISSUES FOR THE 2003 WNV 'SEASON'}

\section{Reporting of probable and/or confirmed human cases}

To document the occurrence of a WNV case or case cluster in a particular health unit or jurisdiction it is necessary to carry out confirmatory tests (see Case definitions, Appendix 1) on appropriate specimens. However, once a certain number of cases have been confirmed in a particular geographical region it is not necessary to do additional or continuous confirmatory testing for the duration of the outbreak. During the 2002 outbreak in the United States, certain states stopped confirmatory testing after an 'adequate' number of human cases of WNV infection were confirmed (CDC, personal communication). Probable cases were then combined with confirmed cases for timely reporting. The CDC Web site (53) provides a section that describes surveillance case definitions and offers the following recommendation: "Once WNV (or SLE virus) has been determined to be the cause of an epidemic/epizootic (eg. By cross-neutralization tests and/or virus isolation from, or direct detection in, humans, birds, or mosquitoes), further cross-neutralization tests generally may be unnecessary to classify human cases for surveillance purposes." Once a limited number of cases have been confirmed in a region, probable cases should be combined with confirmed cases for reporting purposes. However, PRNT could occasionally be performed on a select number of convalescent case samples, especially those with ME and WNV fever, until the end of the 'season'. This protocol would document whether another flavivirus is cocirculating with WNV and involved in human infections. Although unlikely to occur in Canada, this phenomenon was observed in the United States in 2001 and 2002 when cases of SLE and WNV infection were simultaneously occurring in Louisiana (54).

Final decisions on the exact testing algorithms and reporting procedures used will be made at the provincial or health 
unit level. Although the application of higher throughput neutralization assays such as an ELISA-microwell format or the use of vaccine strains of WNV in level two containment will help make the neutralization test less labour intensive and efficient, it is still a very involved assay that requires significant time to perform and for results to be reported. A policy addressing the issue of how many confirmatory tests are required should be in place well before the high risk portion (July to September) of the mosquito season begins.

An additional consideration is the treatment or management of patients. If a suspect case of $\mathrm{ME}$ is detected and a nonconfirmatory diagnostic test on an acute sample provides a high index of suspicion that the patient is infected with a WNV-related virus (eg, titres 1:320 or greater in $\mathrm{HI}$ assay or 3 or greater patient serum to normal human antibody ratios in an IgM ELISA), a report should immediately go out to the physician. This will reduce the probability that inappropriate treatments (eg, antibiotics, providing acyclovir for herpes virus infections, etc) are administered.

Testing of all suspected WNV cases, regardless of the severity of illness, can place a burden on diagnostic laboratories. When laboratory testing capacity is limited, it may be reasonable to prioritize testing based on severity of clinical illness. It is important that this information be communicated to physicians, who can in turn provide the relevant clinical information when requesting testing. This would ensure that priority can be given to the samples for which the results are most needed to guide patient management.

\section{Other surveillance issues}

Over the past three years, surveillance has documented the incursion of WNV into a wide geographic area of Canada. Though virus activity was documented in four provinces for the first time in 2002, recursion has occurred in parts of southern Ontario and WNV may now be endemic in these jurisdictions. It is probable that the range of WNV will continue to expand to include all western provinces and other regions of Atlantic Canada in 2003 or beyond. WNV has caused mortality in wild and domestic bird, horse and other mammal populations. Human cases of WNV infection have resulted in morbidity and mortality though the patterns of human disease appear to be much more focal than that observed in birds or horses. At the present time, the surveillance data cannot be used to predict epizootics or subsequent epidemics of WNV infection. However, outbreaks of WNV infections are likely to occur in the future in some Canadian jurisdictions and surveillance programs do establish that WNV is active in a given jurisdictions, and this information can play a central role in estimating the level of risk for human exposure and formulating a local response to virus activity (ie, informing the public and undertaking vector control activities, if warranted). For these reasons, surveillance should continue in Canada during 2003; however, as in previous years, the program will be modified. For example, it is likely that dead bird testing will be decentralized and will be performed using an antigen capture dipstick assay (eg, VecTest [Medical Analysis Systems Inc, USA]) $(45,55)$ with only confirmation by PCR and/or virus isolation. Likewise, CFIA will make WNV 'notifiable' in 2003 and will track virus activity in domestic veterinary species across Canada.

The front line diagnostic tests used to detect infection in humans will likely be changed to IgM ELISA from HI, confirmation by PRNT will not likely be required for every flavivirus seroconversion and provincial capacity to undertake these tests will be increased so that demands, in the case of large scale outbreaks, can be better met. Although various treatment regimens, such as hyperimmune sera and antivirals, are being considered or undergoing clinical trials (56-58), specific therapy for WNV disease is not currently available. Vaccines are an important consideration, particularly for high risk individuals, such as elderly people, and several research groups are developing and evaluating candidate vaccines in the United States $(59,60)$. However, these will not be available for at least one or two years. Risk of WNV infection can be mitigated by reducing human exposure to mosquitoes through simple personal protective strategies. However, the level of compliance to public health messaging appears to be low and social marketing type strategies, with evaluation of the efficacy of these programs, may need to be undertaken. Lastly, vector control programs are another option for reducing the risk of human infections and implementation of programs to reduce mosquito populations need to be considered seriously in areas where WNV activity may occur or recur and pose a threat to public health.

\section{APPENDIX 1}

\section{Case definitions for WNV meningitis/encephalitis}

Suspect case: A person with a febrile illness AND associated neurological manifestations consistent with a diagnosis of viral meningitis or encephalitis that would include an altered mental status. Altered mental status could range from confusion to coma with or without additional signs of brain dysfunction (eg, paresis or paralysis, cranial nerve palsies, sensory deficits, abnormal reflexes, generalized convulsions and abnormal movements). A significant feature of WN viral encephalitis may be marked muscle weakness, therefore, WNV should be considered in the differential diagnosis of all suspected cases of acute flaccid paralysis or poliomyelitis. Patient history could include travel to an area with confirmed WNV activity in birds, horses, sentinel chickens, mosquitoes or humans.

Probable case: A person exhibiting clinical symptoms and travel history described in the suspect case definition and at least one of the following:

1. A fourfold or greater change in flavivirus HI or IgG ELISA titres in paired acute and convalescent sera. 


\section{APPENDIX 1 (continued)}

2. A single serum sample with a patient serum to normal human antibody ratio 3 or greater in a WNV IgM ELISA (and the patient serum/normal human antibody obtained with WNV antigen is at least twice that obtained with other flavivirus antigens).

Note: If a titre 1:320 or greater is observed in a WNV HI test or an elevated titre is documented in a WNV IgG ELISA, the case may be considered probable with a confirmatory PRNT. However, if WNV cases have been previously documented in an area where the suspect case resides, then it may not be necessary to perform a confirmatory PRNT on single serum sample (or samples with high static titres) for the case to be designated as probable (see "Specimen collection and diagnostic algorithms").

Confirmed case: A confirmed case is a person with febrile illness and neurological symptoms consistent with the suspect case definition and at least one of the following:

1. A fourfold or greater change in HI or IgG ELISA titres, confirmed by the documentation of PRNT antibody titres to WNV in paired acute and convalescent sera or in convalescent sera only.

2. Isolation of WNV from or demonstration of WNV antigen or genomic sequences in tissue, blood, CSF or other body fluids.

3. Demonstration of IgM antibody to WNV in CSF by IgM-capture ELISA with confirmation by PRNT.

CSF Cerebrospinal fluid; HI Hemagglutination inhibition; Ig Immunoglobulin; PRNT Plaque-reduction neutralization test; WNV West Nile virus

\section{REFERENCES}

1. Nash D, Mostashari F, Fine A, et al. The outbreak of West Nile virus infection in the New York City area in 1999. N Engl J Med 2001;344:1807-14.

2. Asnis DS, Conetta R, Teixeira AA, Waldman G, Sampson BA. The West Nile Virus outbreak of 1999 in New York: the Flushing Hospital experience. Clin Infect Dis 2000;30:413-8.

3. Provisional Surveillance Summary of the West Nile Virus Epidemic United States, January-November 2002. MMWR Morb Mortal Wkly Rep 2002;51:1129-33.

4. Mackenzie JS, Barrett ADT, Deubel V. The Japanese encephalitis serological group of flaviviruses: A brief introduction to the group. In: Mackenzie JS, Barrett ADT, Deubel V, eds. Japanese Encephalitis and West Nile Viruses. New York: Springer-Verlag, 2002:1-10.

5. Campbell GL, Marfin AA, Lanciotti RS, Gubler DJ. West Nile virus. Lancet Infect Dis 2002;2:519-29.

6. Kuno G, Chang GJ, Tsuchiya KR, Karabatsos N, Cross CB. Phylogeny of the genus Flavivirus. J Virol 1998;72:73-83.

7. Turell MJ, Sardelis MR, Dohm DJ, O'Guinn ML. Potential North American vectors of West Nile virus. Ann NY Acad Sci 2001;951:317-24.

8. White DJ, Kramer LD, Backenson PB, et al. Mosquito surveillance and polymerase chain reaction detection of West Nile virus, New York State. Emerg Infect Dis 2001;7:643-9.

9. Turrell MJ, Sardelis MR, O'Guinn ML, Dohm DJ. Potential vectors of West Nile virus in North America. In: Mackenzie JS, Barrett ADT, Deubel V, eds. Japanese Encephalitis and West Nile Viruses. New York: Springer-Verlag, 2002:241-52.

10. Bunning ML, Bowen RA, Cropp CB, et al. Experimental infection of horses with West Nile virus. Emerg Infect Dis 2002;8:380-6.

11. Smithburn KC, Hughes TP, Burke AW, Paul JH. A neurotropic virus isolated from the blood of a native of Uganda. Am J Trop Med 1940;20:471-92.

12. Murgue B, Zeller H, Duebel V. The ecology and epidemiology of West Nile virus in Africa, Europe, and Asia. In: Mackenzie JS, Barrett ADT, Deubel V, eds. Japanese Encephalitis and West Nile Viruses. New York: Springer-Verlag, 2002:195-222.

13. Petersen LR, Roehrig JT. West Nile virus: A reemerging global pathogen. Emerg Infect Dis 2001;7:611-4.

14. Malkinson M, Banet C. The role of birds in the ecology of West Nile virus in Europe and Africa. In: Mackenzie JS, Barrett ADT, Deubel V, eds. Japanese Encephalitis and West Nile Viruses. New York: Springer-Verlag, 2002:309-22.

15. Rappole J, Derrickson SR, Hubalek Z. Migratory birds and spread of West Nile virus in the Western Hemisphere. Emerg Infect Dis 2000;6:1-16.
16. Eidson M, Kramer L, Stone W, Hagiwara Y, Schmit K. Dead bird surveillance as an early warning system for West Nile virus. Emerg Infect Dis 2001;7:631-5.

17. Komar N. West Nile viral encephalitis. Rev Sci Tech Off Int Epiz 2000;19:166-76.

18. Anderson JF, Andreadis TG, Vossbrinck CR, et al. Isolation of West Nile virus from mosquitoes, crows, and a Cooper's hawk in Connecticut. Science 1999;286:2331-3.

19. Lanciotti RS, Roehrig JT, Deubel V, et al. Origin of the West Nile virus responsible for an outbreak of encephalitis in the northeastern United States. Science 1999;286:2333-7.

20. Lanciotti RS, Ebel GD, Deubel V, et al. Complete genome sequences and phylogenetic analysis of West Nile virus strains isolated from the United States, Europe, and the Middle East. Virology 2000;298:96-105.

21. Hayes CG. West Nile fever. In: TP Monath, ed. The Arboviruses: Epidemiology and Ecology. Boca Raton: CRC Press, 1989:59-88.

22. Investigative Team, Tsai TF, Popovici F, Cernescu C, Campbell GL, Nedelcu NI. West Nile encephalitis epidemic in southeastern Romania. Lancet 1998;352:767-771.

23. Mostashari F, Bunning ML, Kitsutani PT, et al. Epidemic West Nile encephalitis, New York, 1999: Results of a household-based seroepidemiological survey. Lancet 2001;358:261-4.

24. Nash D, Labowitz A, Maldin B, et al. A follow-up study of persons infected with West Nile virus during a 1999 outbreak in the New York City area. 39th Annual Meeting of the Infectious Diseases Society of America, San Francisco, October 25-28, 2001. [Abst]

25. Sibbald B. Canada will check donor blood for West Nile virus if test available. CMAJ 2003;168:207.

26. Petersen LR. CDC-Fourth National Conference on West Nile Virus in the United States, New Orleans, Louisiana. February 9-11, 2003. $<$ http://www.cdc.gov/ncidod/dvbid/westnile/conf/February_2003.htm \#powerpoint> (Version current at March 17, 2003).

27. Huang C, Slater B, Rudd R, et al. First isolation of West Nile virus from a patient with encephalitis in the United States. Emerg Infect Dis 2002;8:1367-71.

28. Pogodina VV, Frolova MP, Malenko GV, et. al, Study on West Nile virus persistence in monkeys. Arch Virol 1983;75:71-86.

29. Xia S-Y, Guzman H, Zhang H, Travassos APA, Tesh RB. West Nile virus infection in the golden hamster (Mesocricetus auratus): A model for West Nile encephalitis. Emerg Infect Dis 2001;7:714-21.

30. Cardosa MJ, Gordon S, Hirsch S, et al. Interaction of West Nile virus with primary murine macrophages: Role of cell activation and receptors for antibody and complement. J Virol 1986;57:952-9.

31. Southam CMA. Induced virus infections in man by the Egypt 
isolates of West Nile Virus. Am J Trop Med Hyg 1954;3:19-50.

32. Roehrig JT, Nash D, Maldin B, et al. Persistence of virus-reactive serum immunoglobulin $\mathrm{M}$ antibody in confirmed West Nile virus encephalitis cases. Emerg Infect Dis 2003;9:376-9.

33. Petersen LR, Marfin AA. West Nile virus: A primer for the clinician. Ann Intern Med 2002;137:173-9.

34. Leis AA, Stokic DS, Polk JL, Dostrow V, Winkelmann M. A poliomyelitis-like syndrome from West Nile virus infection. N Engl J Med 2002;347:1279-80.

35. Leis AA, Fratkin J, Stokic DS, Harrington T, Webb RM, Slavinski SA. West Nile poliomyelitis. Lancet Infect Dis 2003;3:9-10.

36. Beaty BJ, Calisher CH, Shope RE. Arboviruses. In: Lennette EH, Lennette DA, Lennette ET, eds, Diagnostic procedures for viral, rickettsial, and chlamydial infections, 7th edn. Washington: American Public Health Association, 1995:189-212.

37. Clarke D, Casals J. Techniques for hemagglutination inhibition with arthropod-borne viruses. Am J Trop Med Hyg 1958;7:561-73.

38. Johnson AJ, Martin DA, Karabatsos N, Roehrig JT. Detection of anti-arboviral immunoglobulin $\mathrm{G}$ by using a monoclonal antibodybased capture enzyme-linked immunosorbent assay. J Clin Microbiol 2000;38:1827-31.

39. Martin DA, Biggerstaff BJ, Allen B, Johnson AJ, Lanciotti RS, Roehrig JT. Use of immunoglobulin $\mathrm{M}$ cross-reactions in differential diagnosis of human flaviviral encephalitis infections in the United States. Clin Diagn Lab Immunol 2002;9:544-9.

40. Roehrig JT, Layton M, Smith P, Campbell Nasci R, Lanciotti R. The emergence of West Nile virus in North America: Ecology, Epidemiology, and Surveillance. In: Mackenzie JS, Barrett ADT, Deubel V, eds. Japanese Encephalitis and West Nile Viruses. New York: Springer-Verlag, 2002:223-40.

41. Calisher CH, Karabatsos N, Dalrymple JM, et al. Antigenic relationships between flaviviruses as determined by crossneutralization tests with polyclonal antisera. J Gen Virol 1989;70:37-43.

42. New York Department of Health. West Nile virus surveillance and control: An update for healthcare providers in New York City. New York: City Health Information, 2001;20.

43. Tardei G, Ruta S, Chitu V, Rossi C, Tsai TF, Cernescu C. Evaluation of immunoglobulin M (IgM) and IgG enzyme immunoassays in serologic diagnosis of West Nile virus infection. J Clin Microbiol 2000;38:2232-9.

44. Vorndam V, Beltran M. Enzyme-linked immunosorbent assay-format microneutralization test for dengue viruses. Am J Trop Med Hyg 2002;66:208-12.

45. Nasci RS, Gottfried KL, Burkhalter KI, et al. Comparison of vero cell plaque assay, TaqMan ${ }^{\circledR}$ reverse transcriptase polymerase chain reaction RNA assay, and VecTest ${ }^{\mathrm{TM}}$ antigen assay for detection of West Nile virus in field-collected mosquitoes. J Am Mosq Control
Assoc 2002;18:294-300.

46. Hunt AR, Hall RA, Kerst AJ, et al. Detection of West Nile virus antigen in mosquitoes and avian tissues by a monoclonal antibodybased capture enzyme immunoassay. J Clin Microbiol 2002;40:2023-30.

47. Wiedbrauk DL, Nucleic acid amplification methods. In: Spector S, Hadinka RL, Young SA, eds. Clinical Virology Manual, 3rd edn. Washington: ASM Press, 2000:188-97.

48. Lanciotti RS, Kerst AJ, Nasci RS, et al. Rapid detection of West Nile virus from human clinical specimens, field collected mosquitoes, and avian samples by a TaqMan reverse-transcriptase-PCR assay. J Clin Microbiol 2000;38:4066-71.

49. Lanciotti RS, Kerst AJ. Nucleic acid sequence based amplification assays for rapid detection of West Nile and St. Louis encephalitis viruses. J Clin Microbiol 2001;39:4506-13.

50. Ontario Ministry of Health and Long Term Care, West Nile Virus Updates. <http://www.gov.on.ca/health/english/program/pubhealth/ wnv_mn.html> (Version current at March 17, 2003).

51. Population and Public Health Branch WNV surveillance updates, March 2003. Health Canada. <http://www.hc-sc.gc.ca/pphbdgspsp/wnv-vwn/index.html> (Version current at March 17, 2003).

52. Quebec West Nile virus summary and update. <http://www.msss. gouv.qc.ca/f/sujets/virusnil.htm> (Version current at March 17, 2003).

53. CDC West Nile virus home page. <http://www.cdc.gov/ncidod/ dvbid/westnile/index.htm $>$ (Version not current at March 17, 2003).

54. Louisiana Office of Public Health Web Site. <http://oph.dhh.state.la. us/infectiousdisease/westnile/page06bd.html?page=393> (Version current at March 17, 2003).

55. Komar N, Lanciotti R, Bowen R, et al. Detection of West Nile virus in oral and cloacal swabs collected from bird carcasses. Emerg Infect Dis 2002;8:741-2.

56. Anderson JF, Rahal JJ. Efficacy of interferon alpha-2b and ribavirin against West Nile virus in vitro. Emerg Infect Dis 2002;8:107-8. [Lett]

57. Hamdan A, Green P, Mendelson E, Kramer MR, Pitlik S, Weinberger M. Possible benefit of intravenous immunoglobulin therapy in a lung transplant recipient with West Nile virus encephalitis. Transpl Infect Dis 2002;4:160-2.

58. Shimoni Z, Niven MJ, Pitlick S, Bulvik S. Treatment of West Nile virus encephalitis with intravenous immunoglobulin. Emerg Infect Dis 2001;7(4):759.

59. Tesh RB, Arroyo J, Travassos AP, et al. Efficacy of killed virus vaccine, live attenuated chemeric virus vaccine, and passive immunization for prevention of West Nile virus encephalitis in hamster model. Emerg Infect Dis 2002;8:1392-7.

60. Monath TP. Editorial: Jennerian vaccination against West Nile virus. Am J Trop Med Hyg 2002;66:113-4. 


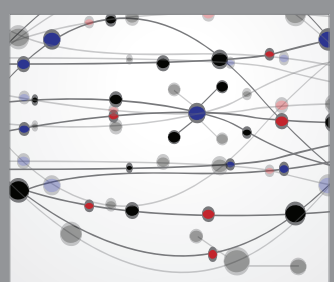

The Scientific World Journal
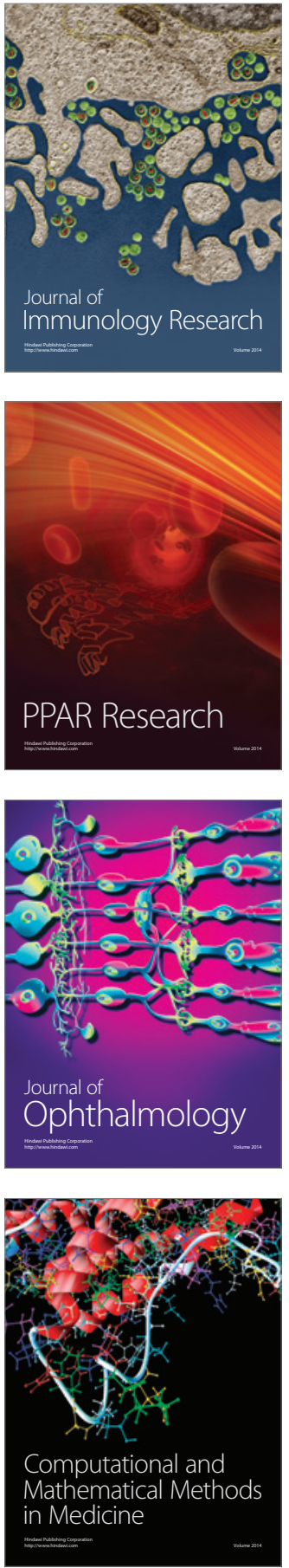

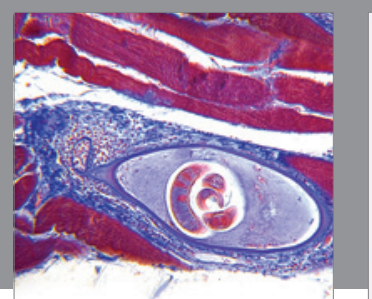

Gastroenterology Research and Practice

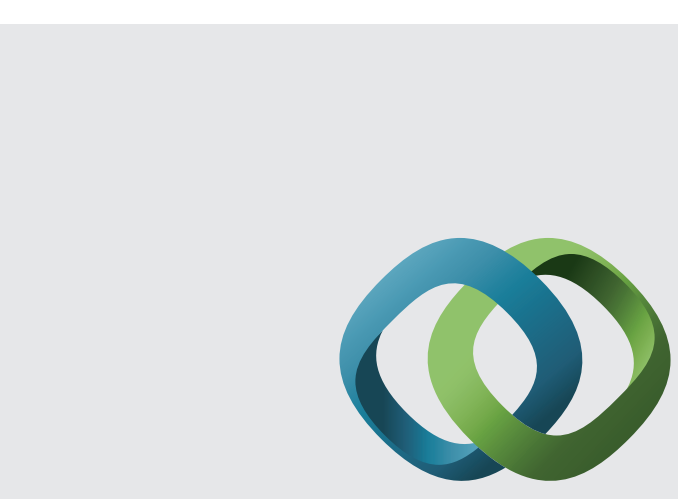

\section{Hindawi}

Submit your manuscripts at

http://www.hindawi.com
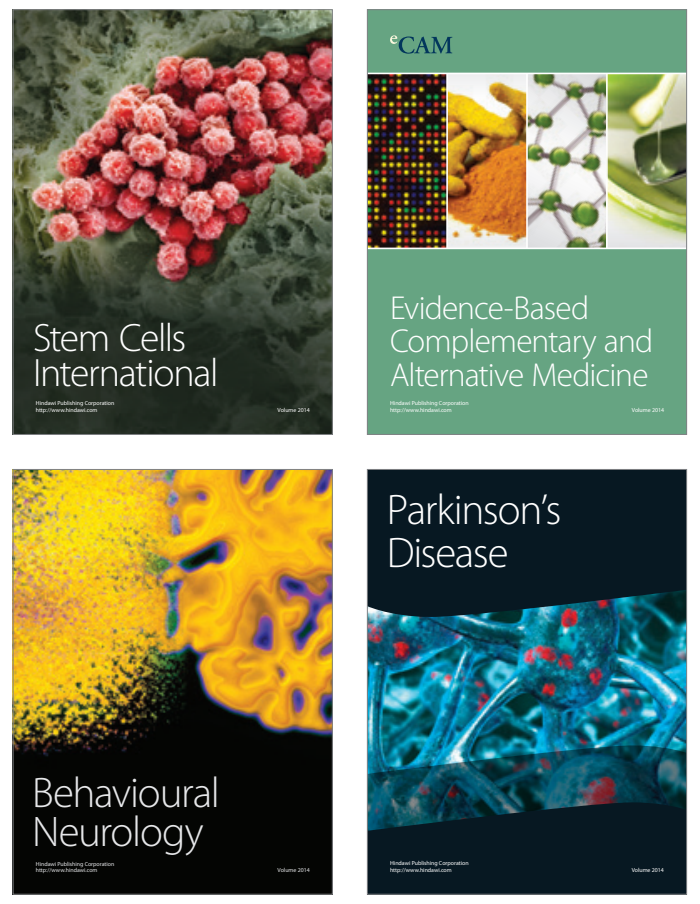
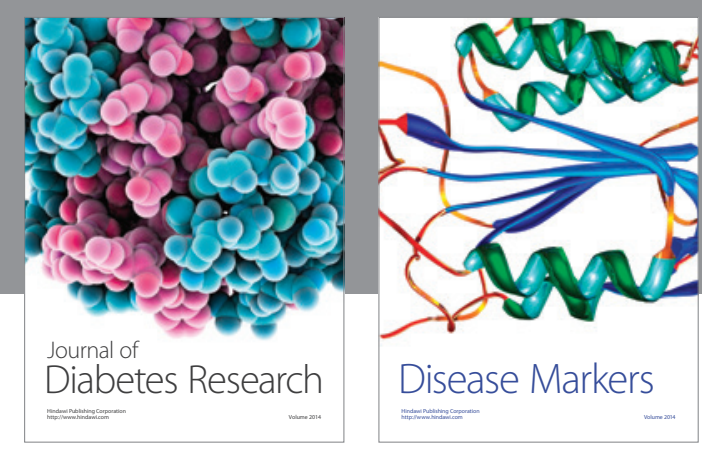

Disease Markers
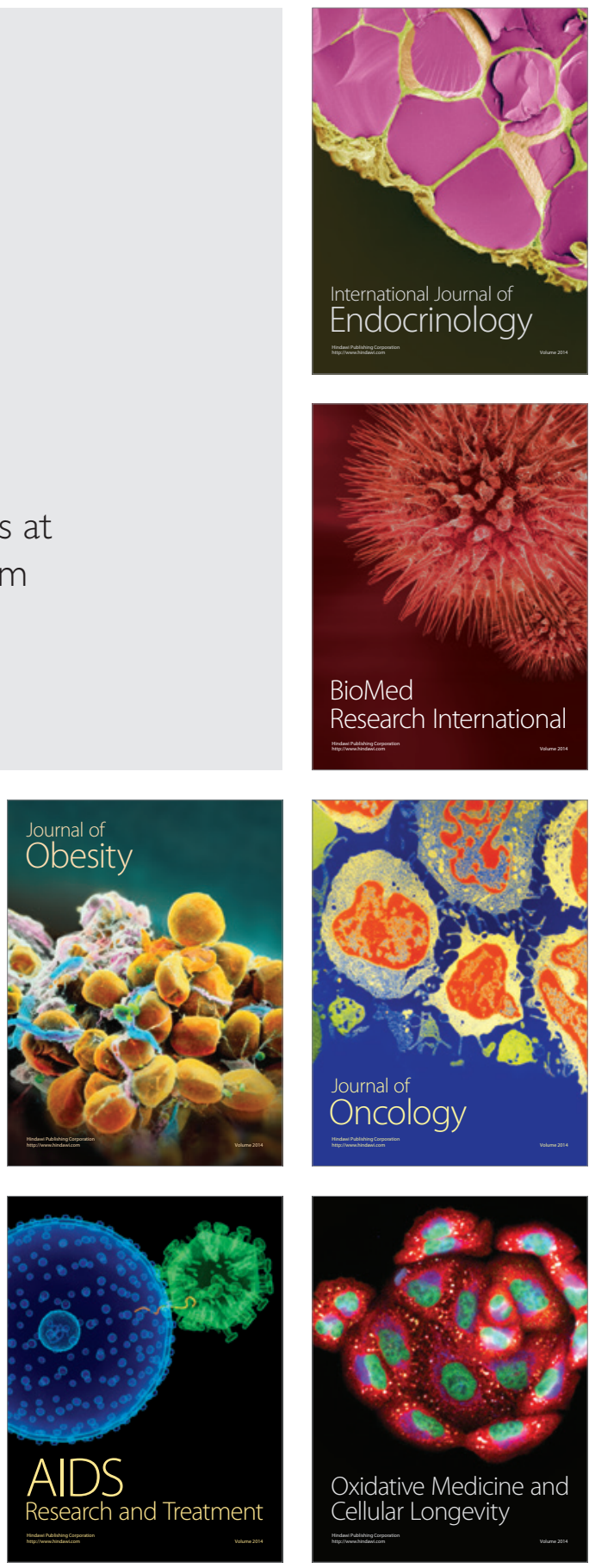